\title{
Prelimbic cortex bdnf knock-down reduces instrumental responding in extinction
}

\author{
Shannon L. Gourley, ${ }^{1,2}$ Jessica L. Howell, ${ }^{1}$ Maribel Rios, ${ }^{3}$ Ralph J. DiLeone, ${ }^{1,4}$ \\ and Jane R. Taylor $1,4,5,6$ \\ ${ }^{1}$ Department of Psychiatry, Yale University, New Haven, Connecticut 06508, USA; ${ }^{2}$ Department of Molecular Biophysics and \\ Biochemistry, Yale University, New Haven, Connecticut 06510, USA; ${ }^{3}$ Departments of Neuroscience and Cellular and Molecular \\ Physiology, Tufts University, Boston, Massachusetts 02111, USA; ${ }^{4}$ Interdepartmental Neuroscience Program, Yale University, New \\ Haven, Connecticut 06510, USA; ${ }^{5}$ Department of Psychology, Yale University, New Haven, Connecticut 06520, USA
}

\begin{abstract}
Anatomically selective medial prefrontal cortical projections regulate the extinction of stimulus-reinforcement associations, but the mechanisms underlying extinction of an instrumental response for reward are less well-defined and may involve structures that regulate goal-directed action. We show brain-derived neurotrophic factor (bdnf) knock-down in the prelimbic, but not orbitofrontal, cortex accelerates the initial extinction of instrumental responding for food and reduces striatal BDNF protein. When knock-down mice were provided with alternative response options to readily obtain reinforcement, extinction of the previously reinforced response was unaffected, consistent with the hypothesis that the prelimbic cortex promotes instrumental action, particularly when reinforcement is uncertain or unavailable.
\end{abstract}

The rodent medial prefrontal cortex contains cytoarchitectonically distinct subregions that can be differentiated based on efferent and afferent projection patterns, with dorsal regionsincluding the dorsal prelimbic cortex (PLc) —sharing similar functions that differ from those of the ventromedial prefrontal cortex, which includes the medial orbitofrontal cortex (mOFC) and infralimbic cortex. These dorsal/ventral networks are considered "go" and "stop" systems, respectively, that coincidentally guide behavior (Heidbreder and Groenewegen 2003). For example, the PLc is essential for maintaining instrumental responding for food when reinforcement is uncertain (Corbit and Balleine 2003; Gourley et al. 2008a). By contrast, ventromedial structures are associated with response inhibition, particularly in the context of stimulus-reinforcement associations (Heidbreder and Groenewegen 2003).

We explore the hypothesis that the PLc may also promote goal-directed responding in the absence of reinforcement, thereby slowing the extinction of a previously reinforced instrumental response. If this is the case, diminution of the biological factors essential for activity-dependent neuroplasticity and cytoskeletal structure within the PLc might be expected to shift the balance between a dorsal "go" network and ventral "stop" network. The consequence would be a rapid decline in instrumental responding during extinction training. Indeed, we report that such a manipulation-virally knocking down BDNF, which promotes long-term potentiation (Kang and Schuman 1995; Korte et al. 1995, 1996; Patterson et al. 1996) and neuronal outgrowth (McAllister et al. 1995, 1996; Xu et al. 2000a,b; Gorski et al. 2003)_ within the PLc facilitates the extinction of instrumental action.

In the first experiment, group-housed $\geq 10$ wk-old male mice bred in-house and homozygous for a floxed $b d n f$ gene (Rios et al. 2001) were anaesthetized with 1:1 2-methyl-2-butanol and tribromoethanol (Sigma Aldrich) diluted 40-fold with saline. Mice were infused into the PLc $(+2.0 \mathrm{AP},-2.8 \mathrm{DV}, \pm 0.1 \mathrm{ML})$ with an adenoassociated virus (AAV) expressing enhanced green fluorescent

${ }^{6}$ Corresponding author.

E-mail jane.taylor@yale.edu; fax (203) 974-7724.

Article is online at http://www.learnmem.org/cgi/doi/10.1101/lm.1547909. protein (EGFP) \pm Cre. With needles (Hamilton Co.) centered at bregma, stereotaxic coordinates were located using Kopf's digital coordinate system with $1 / 100-\mathrm{mm}$ resolution (David Kopf Instruments). Viral constructs were infused over 5 min with $0.5 \mu \mathrm{L} /$ hemisphere; needles were left in place for an additional $4 \mathrm{~min}$. Mice were allowed to recover for at least $2 \mathrm{wk}$, allowing for viralmediated gene knock-down (Berton et al. 2006; Graham et al. 2007; Unger et al. 2007). All procedures were Yale University Animal Care and Use Committee approved.

Mice were then food-restricted (90-min access/day) and trained to perform an instrumental response (nose poke) for food reinforcement using Med-Associates operant conditioning chambers controlled by Med-Associates software. These 25-min training sessions were conducted daily, and one, two, or three responses on one of three apertures were reinforced with a 20-mg grain-based food pellet (variable ratio 2 schedule of reinforcement; Bioserv). Two-factor (knock-down $\times$ session) analysis of variance (ANOVA) with repeated measures (RM) indicated bdnf knock-down did not affect the acquisition of instrumental responding (main effect of infusion and infusion $\times$ session interaction $F s<1$ ) (Fig. 1A).

Response extinction was then tested with 10 15-min nonreinforced sessions (five sessions/day). Here, responses made on the previously active aperture declined as expected $\left(F_{(9,72)}=6.7\right.$, $P<0.001)$. An interaction between group and session for responses on the active aperture was also identified $\left(F_{(9,72)}=2.3, P=0.03\right)$. Tukey's post-hoc tests indicated responses made during session 1 were reduced in knock-down mice $(P=0.002)$ (Fig. 1A). Responses made during session 2 were reduced at a trend level of significance $(P=0.07)$, but responding during other sessions did not differ (all $P$ s $>0.3)$, suggesting PLc bdnf knock-down facilitated initial response suppression, but not necessarily the consolidation or expression of extinction learning (Rescorla and Heth 1975).

Because knock-down could conceivably regulate extinction processes via effects on initial instrumental conditioning, we trained another group of mice to perform the response prior to knock-down. Mice were then matched based on responses made during training, and surgery proceeded. After recovery, mice were given three "reacquisition" sessions identical to training sessions, during which no differences were found for responses made on the 

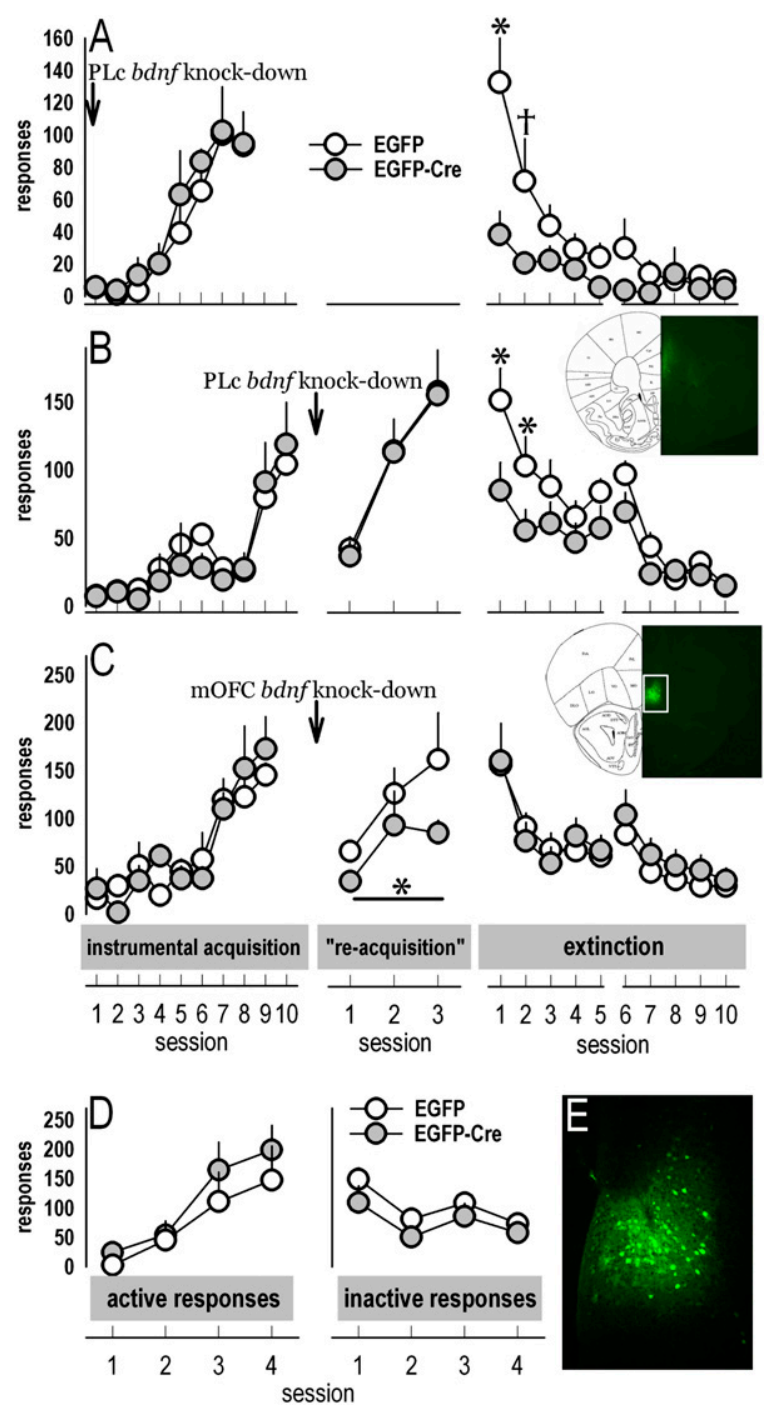

Figure 1. PLc $b d n f$ knock-down decreases instrumental responding in extinction. (A) Viral-mediated PLc $b d n f$ knock-down had no effects on the acquisition of an instrumental response for food. Responses made on the active aperture are shown (left). Responding in extinction was, however, diminished during the first extinction session (right). The break in the extinction curve represents the passage of $1 \mathrm{~d}$. (B) A second group of mice was trained to respond for food before viral construct infusion. Responding during reacquisition reminder sessions after recovery was unaffected, but extinction was again immediately facilitated, as indicated by fewer responses made during sessions 1 and 2. Representative EGFP spread is inset. (C) As a control measure, this experiment was replicated in mice initially trained to perform the task, then given a mOFC, rather than PLc, $b d n f$ knock-down. Although reinforced responding during reacquisition was diminished, responding during extinction was unchanged. Representative EGFP spread is inset. $(D)$ In a reversal task, PLc bdnf knock-down mice did not differ in their ability to "reverse" their responding on an aperture on the opposite side of the chamber; response inhibitionextinction of responding on the previously active aperture-under these circumstances was also unchanged. (E) An enlarged EGFP image is shown (taken from inside the white box in C). EGFP radiates laterally from the infusion site, and the medial wall of the PFC can be seen at left. Symbols represent means (+ SEM) per group $\left({ }^{\star} P<0.05 ;{ }^{\dagger} P=0.07\right)$. Arrows indicate the time of knock-down, relative to testing sessions.

reinforced aperture (main effect of group and interaction $F \mathrm{~s}<1$ ) (Fig. 1B). When reinforcement was withheld, however, bdnf knock-down mice again made fewer responses relative to control mice during sessions 1 and 2 (interaction $F_{(9,135)}=2.3, P=0.02$; post-hoc $P \mathrm{~s}<0.01)$ but not later sessions (Fig. 1B). These data further support our conclusion that PLc bdnf knock-down decreases instrumental responding during the early phases of extinction, but do not indicate whether this effect is behaviorally or anatomically specific. In this group, post-mortem EGFP distribution indicated two mice had only unilateral $b d n f$ knock-down; these animals were excluded.

To address anatomical specificity, we replicated this experiment with $b d n f$ knocked down in the ventrally situated mOFC. This site was chosen over the infralimbic cortex because we had greater confidence we could achieve anatomically selective knockdown in this larger region. Viral constructs were infused over $3 \mathrm{~min}$ with $0.25 \mu \mathrm{L} /$ hemisphere and needles aimed $\mathrm{AP}+2.3$, DV -3.0, ML \pm 0.1 and left in place for an additional $4 \mathrm{~min}$. During reacquisition, a main effect of group on responses made on the active aperture indicated mOFC $b d n f$ knock-down, unlike PLc $b d n f$ knock-down, decreased reinforced responding $\left(F_{(1,9)}=7.9, P=\right.$ 0.02 ; interaction $F<1$ ) (Fig. 1C). No effects of knock-down were, however, detected for responses made during extinction testing (group and interaction $F \mathrm{~s}<1$ ) (Fig. 1C). This profile is distinct from PLc $b d n f$ knock-down mice, in which nonreinforced, but not reinforced, responding was affected. In this group, one animal with unilateral $b d n f$ knock-down was excluded.

To address behavioral specificity, mice from Figure 1B were retrained until responding for food on the active aperture was reinstated. Then, the location of the active aperture was "reversed," such that the previously nonreinforced aperture on the opposite side of the chamber wall was reinforced. In other words, mice trained to respond on the right-side aperture were now reinforced for responding on the left-side aperture and vice versa. This "reversal" procedure allowed us to test whether PLc $b d n f$ knock-down facilitates extinction when reinforcement is available upon the acquisition of an alternative response. We used a highly reinforcing variable ratio 2 schedule, and test sessions lasted $45 \mathrm{~min}$.

Under these conditions, $b d n f$ knock-down and control mice did not differ, responding on both the previously reinforced and the newly reinforced apertures to the same degree as control mice (main effect of genotype on nonreinforced responding $F_{(1,14)}=1.9$, $P=0.2$; reinforced responding $F<1$; group $\times$ session interaction $F<1$ ) (Fig. 1D). In other words, PLc $b d n f$ knock-down mice showed exaggerated response inhibition in the absence of reinforcement, but not when a competing response to obtain food reinforcement was available. Main effects of session on responses made on the active and inactive apertures indicated mice acquired the "reversal" $\left(F_{(3,45)}=15.2, P<0.001 ; F_{(3,45)}=5.7, P=0.002\right.$, respectively).

In a final behavioral experiment, male group-housed C57BL/ $6 \mathrm{~J}$ mice (Charles River Laboratories, Kingston, New York), also $\geq 10$ wk of age at the start of the experiment, were trained and infused with BDNF to evaluate whether acute PLc BDNF infusion produced the opposite effects of gene knock-down: slowed extinction. Human recombinant BDNF (Chemicon) dissolved in sterile saline in a concentration of $0.4 \mu \mathrm{g} / \mu \mathrm{L}$ (Gourley et al. 2008b) was used, with $0.2 \mu \mathrm{L} / \mathrm{site}$ at $\mathrm{AP}+2.0, \mathrm{DV}-2.5, \mathrm{ML} \pm 0.1$ (Gourley et al. 2008a) infused over $2 \mathrm{~min}$ with needles left in place for $2 \mathrm{~min}$ after infusion.

Several studies indicate BDNF has behavioral effects for several days after infusion into the striatum (Horger et al. 1999), ventral tegmental area ( $\mathrm{Lu}$ et al. 2004), hippocampus (Shirayama et al. 2002; Gourley et al. 2008b), and prefrontal cortex (Berglind et al. $2007,2009)$. Therefore, we utilized a single-infusion protocol: Food restriction resumed on day 5 after surgery, at which point mice appeared active. Testing resumed on day 7 , at which point mice were subjected to three nonreinforced test sessions. bdnf knockdown mice were affected during the first and second sessions only, 
so this protocol would be expected to capture the window during which BDNF had effects, if any. These mice showed the typical reduction of responding across sessions $\left(F_{(2,14)}=8.6, P=0.004\right)$ (Fig. $2)$. It is worth noting that responding in control mice was lower than in previous experiments; this is likely due to the more limited recovery and food restriction time after surgery. Nonetheless, we found no effect of BDNF on responding $(F<1$; infusion $\times$ session interaction $\left.F_{(2,14)}=1.4, P=0.3\right)$.

To verify a physiological response to PLc BDNF infusions (despite a lack of behavioral effect), we rapidly euthanized mice after the last session and extracted and weighed the adrenal glands, which secrete the hormone, corticosterone. Corticosterone secretion is sensitive to medial prefrontal cortex lesions (Diorio et al. 1993; Rangel et al. 2003) and noradrenergic depletion (Radley et al. 2008), and adrenal weights correlate with PLc BDNF expression levels (Gourley et al. 2008a). As expected, BDNFinfused mice had lighter adrenal glands $\left(t_{(10)}=4.2, P=0.002\right)$ (Fig. 2), indicating effects of BDNF infusion were detectable on this measure, though not on response diminution per se.

Local bdnf knock-down could conceivably act in part by retarding anterograde BDNF transport to, or BDNF synthesis in, major PLc projections sites (Sobreviela et al. 1996; Altar et al. 1997; Conner et al. 1997; Kokaia et al. 1998). BDNF in those projection regions-the dorsal and ventral striatum and multiple hypothalamic subregions (Öngür and Price 2000) -as well as in the PLc itself, was therefore quantified by enzyme-linked immunosorbent assay (ELISA; Promega) in knock-down, control, and BDNFinfused mice.

Brains were rapidly harvested from extinguished mice in Figures $1 \mathrm{~A}$ and 2, and frozen and sliced into 1-mm-thick coronal sections. Brain regions were dissected bilaterally or with a single midline extraction by tissue punch (1.2-mm diameter). Tissue was then sonicated in lysis buffer $(200 \mu \mathrm{L}: 137 \mathrm{mM} \mathrm{NaCl}, 20 \mathrm{mM}$ trisHcl [pH 8], 1\% igepal, 10\% glycerol, 1:100 Phosphatase Inhibitor Cocktails 1 and 2; Sigma) and stored at $-80^{\circ} \mathrm{C}$. ELISAs were conducted using $65 \mu \mathrm{L} /$ sample/well and in accordance with manufacturer's instructions. BDNF concentrations were normalized to each sample's total protein concentration, as determined by Bradford colorimetric protein assay (Pierce). BDNF was analyzed by ANOVA or ANOVA-on-Ranks for non-normally distributed PLc values.

In the PLc, BDNF was diminished in $b d n f$ knock-down mice as expected $\left(H_{(2,18)}=0.2, P=0.006\right.$, post-hoc $\left.P \mathrm{~s}<0.05\right)$, but BDNF expression in BDNF-infused mice did not differ from the control group $(P>0.05)$ (Fig. 3A). BDNF in the hypothalamus $\left(F_{(2,19)}=2.6\right.$, $P=0.1)$ and nucleus accumbens $(F<1)$ was not affected. By

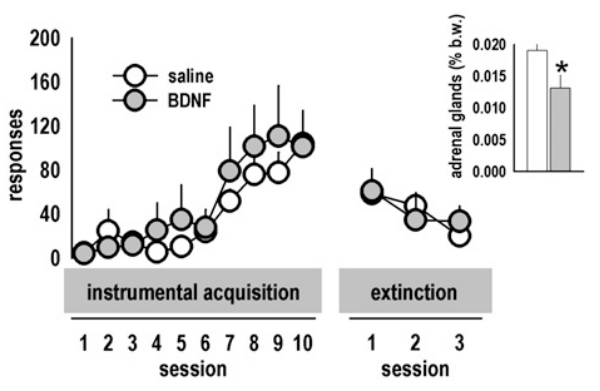

Figure 2. Effects of PLC BDNF microinfusion. Mice were initially trained to perform the nose poke response for food. Responses on the active aperture during training are shown at left. Mice were then infused with BDNF; subsequent instrumental responding during extinction was unaffected. (Inset) Adrenal glands were extracted and weighed after the last extinction session as a measure expected to be sensitive to PLc manipulations. Here, BDNF decreased gland weights (represented as the weight of both glands normalized to total body weight). Symbols represent means (+ SEM) per group, ${ }^{*} P<0.05$.
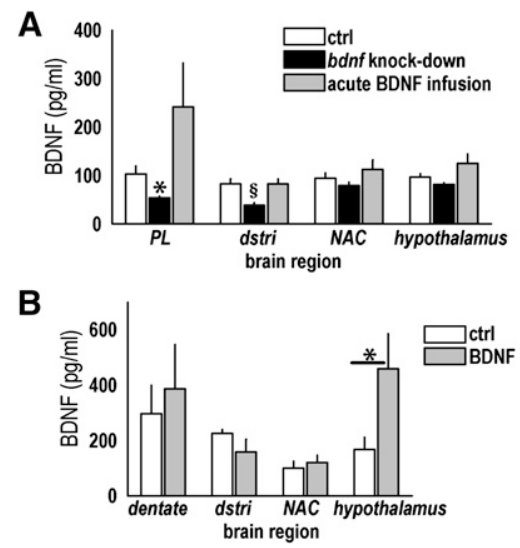

Figure 3. Quantification of BDNF in the PLC, dentate gyrus, and downstream projection sites. $(A)$ BDNF was quantified in the PLC and major projection sites after viral-mediated gene knock-down or acute microinfusion. BDNF was diminished in the PLc of knock-down mice as expected. BDNF was also reduced in the dorsal striatum (dstri) of these animals, while other regions were unaffected by this manipulation. NAC refers to the nucleus accumbens. (B) To confirm the effects of acute BDNF infusion could be detected under some circumstances, tissue from mice infused with BDNF into the dentate gyrus (dentate) was also analyzed. Under these circumstances, elevated BDNF was detected in the hypothalamus. ${ }^{*} P<0.05$ relative to control and BDNF-infused groups; ${ }^{\circledR} P<$ 0.05 relative to BDNF-infused mice; and $P=0.09$ relative to control mice.

contrast, dorsal (primarily dorsomedial) striatal BDNF expression differed between groups $\left(F_{(2,20)}=5.4, P=0.01\right)$, with knock-down mice expressing less BDNF than the BDNF-infused group $(P=$ 0.01). BDNF in knock-down mice did not, however, significantly differ from control mice $(P=0.09)$.

For additional analyses, we conducted ELISAs on tissue from drug-naïve mice that had had a BDNF infusion of the same volume and concentration in the dorsal hippocampus, rather than PLc. As here, these animals had been subsequently tested in an instrumental conditioning task and were sacrificed $7 \mathrm{~d}$ after infusion (for behavioral reports, see Fig. 4 in Gourley et al. 2008b). Like the PLc, the hippocampus projects to the striatum and hypothalamus (Groenewegen et al. 1987; Kishi et al. 2000). In this instance of acute hippocampal infusion, BDNF expression was increased in hypothalamic samples (infusion $\times$ brain region interaction $F_{(3,27)}=3.5, P=0.03$, post-hoc $\left.P=0.009\right)$, consistent with previous findings (Sobreviela et al. 1996). Other regions were not affected (Ps > 0.6) (Fig. 3B).

Taken together, these data indicate long-term distal effects of acute BDNF infusion are detectable when BDNF is infused into the dorsal hippocampus, though not necessarily PLc. Our data do not preclude the possibility, however, that acute PLc BDNF infusion has long-term consequences for BDNF-regulated intracellular signaling cascades in these downstream sites. For example, extracellular-signal regulated kinase $1 / 2$ phosphorylation in the nucleus accumbens is enhanced by single BDNF infusions aimed at the anterior cingulate/PLc border (Berglind et al. 2007).

To summarize, we provide evidence for decreased responding in instrumentally trained mice with PLc-selective $b d n f$ knockdown tested in extinction. Recall of extinction learning did not appear to be affected, as group differences were restricted to test sessions 1 and 2. Time of instrumental training was not a factor, as mice trained to respond for food both before and after knockdown showed a characteristically rapid decline in responding when reinforcement was withheld.

Testing mice in a spatial "reversal" task, in which mice learn simultaneously to inhibit responding on one operant and respond instead on a previously nonreinforced operant, eliminated 
differences in nonreinforced responding between groups. In other words, in the presence of positive reinforcement, knock-down mice did not show exaggerated response inhibition. This behavioral pattern is consistent with the PLc's role in maintaining goaldirected action particularly under low-reinforcement conditions (Corbit and Balleine 2003; Gourley et al. 2008a). If PLc $b d n f$ played a more general role in extinction learning, one would expect PLc $b d n f$ knock-down mice to show rapid response diminution regardless of whether reinforcement was readily available or not, but our reversal experiment clearly illustrated this was not the case.

BDNF ELISA indicated the gene knock-down protocol utilized here results in an $\sim 48 \%$ reduction in BDNF within the PLc and a modest reduction in the downstream dorsal striatum, providing direct evidence for effects of $b d n f$ knock-down on PLc projection neurons (though local interneurons would also be expected to have been infected). Such effects on striatal BDNF expression may be selective to chronic manipulations, as our acute infusion protocol had no consequences for expression in downstream regions, despite actions on a peripheral measure (adrenal gland weight) and evidence of downstream effects after hippocampal infusion.

While we report $b d n f$ knock-down rapidly decreased responding early in extinction, we found that acute BDNF infusion had no effects. How might we reconcile these findings? First, it is possible that prefrontal BDNF overexpression must be chronic to have behavioral effects in this task. Second, supraphysiological BDNFinduced structural destabilization and neuronal remodeling (Horch et al. 1999; Horch and Katz 2002) or activation of cortical interneurons (Rutherford et al. 1998) may have counteracted any effects on extinction. Cortical interneuron activation in particulara process thought to stabilize cortical activity to maintain homeostasis in local circuits-could conceivably negate any effects of BDNF infusion on prefrontal projection neurons (cf., Turrigiano and Nelson 2004; see also Berglind et al. 2007). Last, while single prefrontal BDNF infusions have been reported to suppress cueinduced drug-seeking behavior (Berglind et al. 2007, 2009), such effects may be more acute and/or selectively mediated by Pavlovian, rather than instrumental, processes.

Traditionally, extinction research has focused on Pavlovian fear extinction, in which the infralimbic cortex, and not PLc, is considered the major regulatory site (Quirk and Mueller 2008). Our findings suggest the PLc may, however, be indirectly involved in instrumental extinction, as $b d n f$ knock-down facilitated rapid response diminution in the absence of reinforcement, but not when a competing response was reinforced. These findings are consistent with the idea that under normal circumstances, the PLc invigorates responding by maintaining sensitivity to reinforcement previously available upon completion of a particular instrumental action (Corbit and Balleine 2003) or previously associated with a Pavlovian cue (Vidal-Gonzalez et al. 2006). Future studies will address whether PLc BDNF is indeed critical to the maintenance of action-outcome behavior, since the mechanisms of goal-directedness are not well-characterized. This is despite the possibility that their identification may aid in therapeutically facilitating goal-directed action when response extinction is an unproductive behavioral choice.

\section{Acknowledgments}

We thank Andrea Jacobs for her contributions to pilot studies. This work was supported by PHS DA011717, MH066172 (J.R.T.), MH079680 (S.L.G.), and the Connecticut Department of Mental Health and Addiction Services (J.R.T., R.J.D.). We also acknowledge support from the Interdisciplinary Research Consortium on Stress, Self-control and Addiction (UL1-DE19586 and the NIH Roadmap for Medial Research/Common Fund, AA017537).

\section{References}

Altar CA, Cai N, Bliven T, Juhasz M, Conner JM, Acheson AL, Lindsay RM, Wiegand SJ. 1997. Anterograde transport of brain-derived neurotrophic factor and its role in the brain. Nature 389: 856-860.

Berglind WJ, See RE, Fuchs RA, Ghee SM, Whitfield TW Jr, Miller SW, McGinty JF. 2007. A BDNF infusion into the medial prefrontal cortex suppresses cocaine seeking in rats. Eur J Neurosci 26: 757-766.

Berglind WJ, Whitfield TW, LaLumiere RT, Kalivas PW, McGinty JF. 2009. A single intra-PFC infusion of BDNF prevents cocaine-induced alterations in extracellular glutamate within the nucleus accumbens. J Neurosci 29: 3715-3719.

Berton O, McClung CA, DiLeone RJ, Krishnan V, Renthal W, Russo SJ, Graham D, Tsankova NM, Bolanos CA, Rios M, et al. 2006. Essential role of BDNF in the mesolimbic dopamine pathway in social defeat stress. Science 311: 865-868.

Conner JM, Lauterborn JC, Yan Q, Gall CM, Varon S. 1997. Distribution of brain-derived neurotrophic factor (BDNF) protein and mRNA in the normal adult rat CNS: Evidence for anterograde axonal transport. 17: 2295-2313.

Corbit LH, Balleine BW. 2003. The role of the prelimbic cortex in instrumental conditioning. Behav Brain Res 146: 145-157.

Diorio D, Viau V, Meaney MJ. 1993. The role of the medial prefrontal cortex (cingulate gyrus) in the regulation of hypothalamic-pituitary-adrenal responses to stress. J Neurosci 13: 3839-3847.

Gourley SL, Wu FJ, Taylor JR. 2008a. Corticosterone regulates pERK1/2 MAP kinase in a chronic depression model. Ann N Y Acad Sci 1148: 509_ 514.

Gourley SL, Kiraly DD, Howell JL, Olausson P, Taylor JR. 2008b. Acute hippocampal BDNF restores motivational and forced swim performance after corticosterone. Biol Psychiatry 664: 884-890.

Gorski JA, Zeiler SR, Tamowski S, Jones KR. 2003. Brain-derived neurotrophic factor is required for the maintenance of cortical dendrites. J Neurosci 23: 6856-6865.

Graham DL, Edwards S, Bachtell RK, DiLeone RJ, Rios M, Self DW. 2007. Dynamic BDNF activity in nucleus accumbens with cocaine use increases self-administration and relapse. Nat Neurosci 10: 1029-1037.

Groenewegen HJ, Vermeulen-Van der Zee E, de Kortschot A, Witter MP. 1987. Organization of the projections from the subiculum to the ventral striatum in the rat: A study using anterograde transport of Phaseolus vulgaris leucoagglutinin. Neuroscience 23: 103-120.

Heidbreder CA, Groenewegen HJ. 2003. The medial prefrontal cortex in the rat: Evidence for a dorso-ventral distinction based upon functional and anatomical characteristics. Neurosci Biobehav Rev 27: 555-579.

Horch HW, Katz LC. 2002. BDNF released from single cells elicits local dendritic growth in nearby neurons. Nat Neurosci 5: 1177-1184.

Horch HW, Krüttgen A, Portbury SD, Katz LC. 1999. Destabilization of cortical dendrites and spines by BDNF. Neuron 23: 353-364.

Horger BA, Iyasere CA, Berhow MT, Messer CJ, Nestler EJ, Taylor JR. 1999. Enhancement of locomotor activity and conditioned reward to cocaine by brain-derived neurotrophic factor. J Neurosci 19: 4110-4122.

Kang H, Schuman EM. 1995. Long-lasting neurotrophin-induced enhancement of synaptic transmission in the adult hippocampus. Science 267: 1658-1662.

Kishi T, Tsumori T, Ono K, Yokota S, Ishino H, Yasui Y. 2000. Topographical organization of projections from the subiculum to the hypothalamus in the rat. J Comp Neurol 419: 205-222.

Kokaia Z, Andsberg G, Yan Q, Lindvall O. 1998. Rapid alterations of BDNF protein levels in the rat brain after focal ischemia: Evidence for increased synthesis and anterograde axonal transport. Exp Neurol 154: 289-301.

Korte M, Carroll P, Wolf E, Brem G, Thoenen H, Bonhoeffer T. 1995. Hippocampal long-term potentiation is impaired in mice lacking brain-derived neurotrophic factor. Proc Natl Acad Sci 92: 8856-8860.

Korte M, Griesbeck O, Gravel C, Carroll P, Staiger V, Thoenen H, Bonhoeffer T. 1996. Virus-mediated gene transfer into hippocampal CA1 region restores long-term potentiation in brain-derived neurotrophic factor mutant mice. Proc Natl Acad Sci 93: 12547-12552.

Lu L, Dempsey J, Liu SY, Bossert JM, Shaham Y. 2004. A single infusion of brain-derived neurotrophic factor into the ventral tegmental area induces long-lasting potentiation of cocaine seeking after withdrawal. $J$ Neurosci 24: 1604-1611.

McAllister AK, Lo DC, Katz LC. 1995. Neurotrophins regulate dendritic growth in developing visual cortex. Neuron 15: 791-803.

McAllister AK, Katz LC, Lo DC. 1996. Neurotrophin regulation of cortical dendritic growth requires activity. Neuron 17: 1057-1064.

Öngür D, Price JL. 2000. The organization of networks within the orbital and medial prefrontal cortex of rats, monkeys, and humans. Cereb Cortex 10: 206-219. 
Patterson SL, Abel T, Deuel TA, Martin KC, Rose JC, Kandel ER. 1996. Recombinant BDNF rescues deficits in basal synaptic transmission and hippocampal LTP in BDNF knockout mice. Neuron 16: 1137-1145.

Quirk GJ, Mueller D. 2008. Neural mechanisms of extinction learning and retrieval. Neuropsychopharmacol Rev 33: 56-72.

Radley JJ, Williams B, Sawchenko PE. 2008. Noradrenergic innervation of the dorsal medial prefrontal cortex modulates hypothalamopituitary-adrenal response to acute emotional stress. J Neurosci 28: 5806-5816.

Rangel A, Gonzalez LE, Villarroel V, Hernandez L. 2003. Anxiolysis followed by anxiogenesis relates to coping and corticosterone after medial prefrontal cortical damage in rats. Brain Res 992: 96-103.

Rescorla RA, Heth CD. 1975. Reinstatement of fear to an extinguished conditioned stimulus. I Exp Psychol Anim Behav Process 1: 88-96.

Rios M, Fan G, Fekete C, Kelly J, Bates B, Kuehn R, Lechan RM, Jaenisch R. 2001. Conditional deletion of brain-derived neurotrophic factor in the postnatal brain leads to obesity and hyperactivity. Mol Endocrinol 15: 1748-1757.

Rutherford LC, Nelson SB, Turrigiano GG. 1998. BDNF has opposite effects on the quantal amplitude of pyramidal neuron and interneuron excitatory synapses. Neuron 21: 521-530.

Shirayama Y, Chen AC-H, Nakagawa S, Russell DS, Duman RS. 2002. Brainderived neurotrophic factor produces antidepressant effects in behavioral models of depression. J Neurosci 22: 3251-3261.
Sobreviela T, Pagcatipunan M, Kroin JS, Mufson EJ. 1996. Retrograde transport of brain-derived neurotrophic factor (BDNF) following infusion in neo- and limbic cortex in rat: Relationship to BDNF mRNA expressing neurons. J Comp Neurol 375: 417-444.

Turrigiano GG, Nelson SB. 2004. Homeostatic plasticity within the developing nervous system. Nat Rev Neurosci 5: 97-107.

Unger TJ, Calderon GA, Bradley LC, Sena-Esteves M, Rios M. 2007. Selective deletion of $b d n f$ in the ventromedial and dorsomedial hypothalamus of adult mice results in hyperphagic behavior and obesity. J Neurosci 27: 14265-14274.

Vidal-Gonzalez I, Vidal-Gonzalez B, Rauch SL, Quirk GJ. 2006. Microstimulation reveals opposing influences of prelimbic and infralimbic cortex on the expression of conditioned fear. Learn Mem 13: 728-733.

Xu B, Zang K, Ruff NL, Zhang YA, McConnell SK, Stryker MP, Reichardt LF. 2000a. Cortical degeneration in the absence of neurotrophin signaling. Neuron 26: 233-245.

Xu B, Gottschalk W, Chow A, Wilson RI, Schnell E, Zang K, Wang D, Nicoll RA, Lu B, Reichardt LF. 2000b. The role of brain-derived neurotrophic factor receptors in the mature hippocampus: Modulation of long-term potentiation through a presynaptic mechanism involving TrkB.J Neurosci 20: 6888-6897.

Received July 17, 2009; accepted in revised form September 23, 2009. 


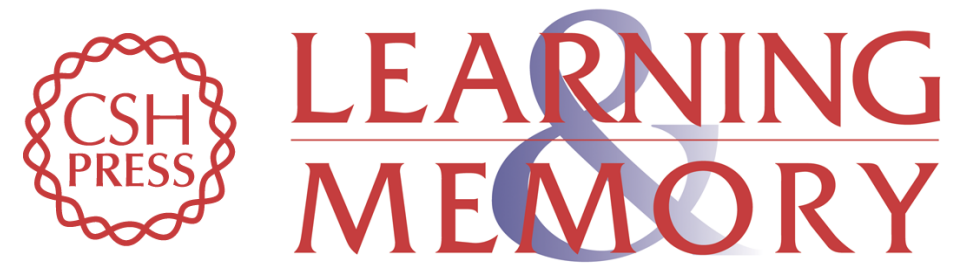

\section{Prelimbic cortex bdnf knock-down reduces instrumental responding in extinction}

Shannon L. Gourley, Jessica L. Howell, Maribel Rios, et al.

Learn. Mem. 2009, 16:

Access the most recent version at doi:10.1101//m.1547909

References This article cites 38 articles, 13 of which can be accessed free at: http://learnmem.cshlp.org/content/16/12/756.full.html\#ref-list-1

License

Email Alerting

Receive free email alerts when new articles cite this article - sign up in the box at the Service top right corner of the article or click here. 